\title{
Correction to: Predictors of cerclage failure in patients with singleton pregnancy undergoing prophylactic cervical cerclage
}

\author{
K. Taghavi ${ }^{1}$ (D) M. L. Gasparri ${ }^{1}$ D. Bolla ${ }^{1} \cdot$ D. Surbek ${ }^{1}$
}

Published online: 5 March 2018

๑) Springer-Verlag GmbH Germany, part of Springer Nature 2018

\section{Correction to: \\ Archives of Gynecology and Obstetrics \\ (2018) 297:347-352 \\ https://doi.org/10.1007/s00404-017-4600-9}

The original version of this article unfortunately contained a mistake. The presentation of Table 3 was incorrect. The corrected Table 3 is given below.

Table 3 Univariate and multivariate analysis of factors associated to early preterm delivery after prophylactic cerclage (all patients, $n=39$ )

\begin{tabular}{|c|c|c|c|c|}
\hline & \multicolumn{4}{|c|}{ Early preterm delivery } \\
\hline & \multicolumn{2}{|l|}{ Univariate analysis } & \multicolumn{2}{|c|}{ Multivariate analysis } \\
\hline & OR $(95 \% \mathrm{CI})$ & $p$ & OR $(95 \% \mathrm{CI})$ & $p$ \\
\hline Age & $1.12(0.96,1.30)$ & $\mathbf{0 . 1 3 2}$ & $1.13(0.95,1.34)$ & 0.153 \\
\hline BMI & $0.94(0.83,1.08)$ & 0.427 & & \\
\hline History of conization (yes/no) & $1.33(0.19,0.02)$ & 0.768 & & \\
\hline History of instrumentation of uterus (yes/no) & $6.67(1.47,30.2)$ & 0.014 & $6.83(1.38,33.8)$ & 0.019 \\
\hline Cervical swabs prior to cerclage (pos/neg) & $0.61(0.13,2.74)$ & 0.521 & & \\
\hline History of II trimester miscarriage (yes/no) & $0.75(0.11,5.07)$ & 0.768 & & \\
\hline $\mathrm{CPR}$ value after cerclage & $0.91(0.75,1.10)$ & 0.346 & & \\
\hline GA at the cerclage & $0.93(0.79,1.09)$ & 0.384 & & \\
\hline Delta-US at 10 days after cerclage & $0.96(0.91,1.01)$ & 0.139 & $0.97(0.91,1.04)$ & 0.478 \\
\hline
\end{tabular}

In bold are reported the $p$ values of variables that from the univariate analysis were selected for multivariate analysis $(\leq 0.2)$ and the $p$ value of the only significant variable $(<0.05)$ at multivariate analysis Multivariable models were carried out for variables reporting a $p$ value $\leq 0.2$ in univariate analysis

The original article can be found online at https://doi.org/10.1007/ s00404-017-4600-9.

K. Taghavi

katayoun.taghavi@gmail.com

1 Department for Obstetrics, University Hospital Bern, 3010 Bern, Switzerland 